\title{
О природе повышения подвижности электронов в канале инверсии у границы раздела кремний-окисел после полевого воздействия
}

\author{
(C) Е.И. Гольдман ${ }^{1}$, А.Э. Набиев ${ }^{2}$, В.Г. Нарышкина ${ }^{1}$, Г.В. Чучева ${ }^{1}$ \\ ${ }^{1}$ Фрязинский фрилиал Института радиотехники и электроники им. В.А. Котельникова Росскийской академии наук, \\ 141190 Фрязино, Московская обл., Россия \\ ${ }^{2}$ Азербайджанский государственный педагогический университет, \\ Az-1000 Баку, Азербайджан \\ E-mail: gvc@ms.ire.rssi.ru
}

(Получена 12 марта 2018 г. Принята к печати 19 марта 2018 г.)

В диапазоне значений индукции поперечного магнитного поля 0-5 Тл при температурах от 100 до $200 \mathrm{~K}$ проведены измерения характеристик проводимости канала инверсии Si-транзисторных структур после ионной поляризации и деполяризации образцов. После ионной поляризации при температуре $420 \mathrm{~K}$ под действием сильного электрического поля в окисле перетекало не менее $6 \cdot 10^{13} \mathrm{~cm}^{-2}$ ионов. Обнаруженное ранее повышение проводимости в цепи исток-сток после поляризации изолирующих слоев до 10 раз объяснено образованием нового пути электропереноса по поверхностной примесной зоне, связанной с делокализованными $\mathrm{D}^{-}$-состояниями, которые генерируются нейтрализованными ионами, расположенными в изолирующем слое у границы раздела с полупроводником.

DOI: 10.21883/FTP.2019.01.46993.8860

\section{1. Введение}

Ионная поляризация изолирующих слоев - это важный инструмент модификации электронных свойств границ раздела (ГР) в структурах металл-диэлектрикполупроводник (МДП). Следствиями поляризации являются не только сдвиги пороговых напряжений открытия каналов инверсии за счет накопления встроенного заряда [1], но и глубокие изменения зонной структуры проводящих путей в связи с образованием высокой концентрации примесных локализованных состояний у ГР полупроводник-диэлектрик [2,3]. Укажем и на возможности создания регулярного распределения локализованного заряда с двумерным потенциальным рельефом, формирующим у поверхности полупроводника различные квантово-размерные наномасштабные области [4,5]. Проведенные ранее эксперименты [6,7] показали, что ионная поляризация транзисторных структур металл-окиселполупроводник (МОП) приводит к аномально высокому увеличению (в несколько раз) эффективной подвижности электронов в канале инверсии у ГР $\mathrm{Si}-\mathrm{SiO}_{2}$. При этом механизм повышения проводимости в цепи истоксток после полевого воздействия на окисел кремния до сих пор оставался непонятным. Цель данной работы прояснение природы данного явления на основе анализа большого объема экспериментальных данных о вольтамперных характеристиках транзистора в состояниях после поляризации и деполяризации при различных температурах и об изменении проводящих свойств канала инверсии под действием магнитных полей.

\section{2. Эксперимент}

Опыты проводились на $\mathrm{Si}-\mathrm{MOП-транзисторах} \mathrm{с} \mathrm{элек-}$ тронным каналом инверсии и с толщиной термического подзатворного окисла $h=1000 \AA$, шириной электродов исток-сток $W=1$ мм и расстоянием между ними $L=10$ мкм. Транзисторы формировались по стандартной кремниевой технологии. Измерения проводились на компьютеризованной установке [8]. Поляризация окисла осуществлялась при напряжениях на затворе $V_{g}=10 \mathrm{~B}$ и на стоке $V_{d}=0.01 \mathrm{~B}$ в течение 1 ч при температуре 420 K. После завершения поляризации при неизменных значениях напряжений транзистор охлаждался до комнатной температуры. Деполяризация проводилась аналогично, но при напряжении на затворе $V_{g}=-10 \mathrm{~B}$. Сразу после полевых и температурных воздействий образец помещался в криомагнитную безжидкостную систему, позволяющую измерять токи и напряжения в диапазоне температур от 300 до $6 \mathrm{~K}$ и в магнитных полях до 8 Тл [9]. Поскольку при комнатной температуре в сильных электрических полях дрейф ионов может изменять состояние образцов, опыты проводились не выше 200 K. Температура транзистора контролировалась с помощью терморегулятора Lakeshore 335 с точностью $0.01^{\circ}$.

\section{3. Обсуждение результатов}

На рис. 1 представлены результаты измерений зависимостей токов в канале инверсии от напряжения затвора после ионной поляризации и деполяризации соответственно при различных температурах. Особенностью исследованных образцов являются высокие токи утечки в цепи затвор-подложка, примерно $5 \cdot 10^{-11} \mathrm{~A}$, что существенно больше токов, связанных с дрейфом ионов при поляризации и деполяризации соответственно. ${ }^{1}$ Тем не

\footnotetext{
${ }^{1}$ Подобные результаты, но в меньшем объеме, получались и ранее [6] на сходных образцах.
} 


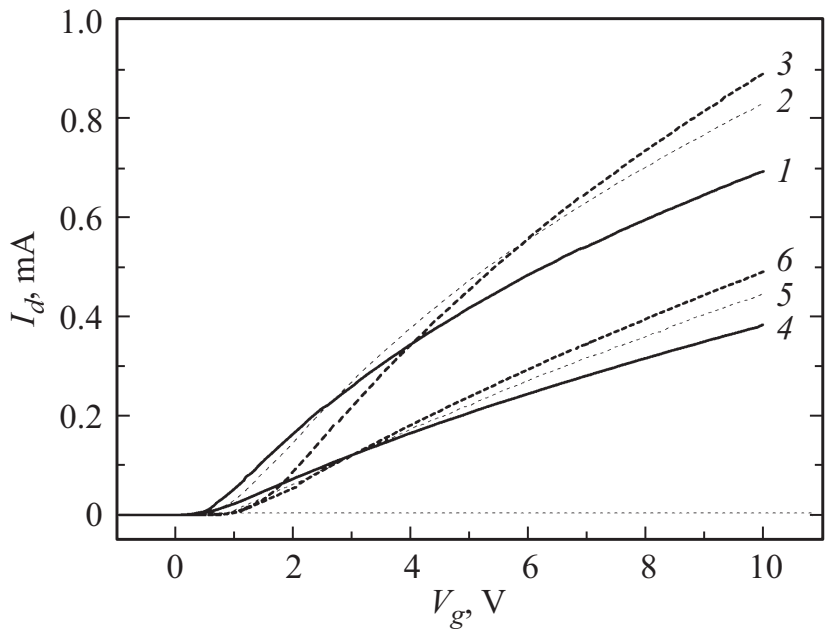

Рис. 1. Омические токи в канале инверсии транзистора после ионной поляризации (кривые $1-3$ ) и деполяризации (кривые 4-6); номера кривых: $1,4-200 \mathrm{~K} ; 2,5-150 \mathrm{~K}$; $3,6-100 \mathrm{~K} ; V_{d}=0.01 \mathrm{~B}$.

менее, исходя из сходности образцов и полученных в [6] данных, можно считать, что при температуре $420 \mathrm{~K}$ под действием сильного поля в окисле перетекает не менее $6 \cdot 10^{13} \mathrm{~cm}^{-2}$ ионов. Поэтому из рис. 1 следует, что переход из деполяризованного состояния в поляризованное относительно слабо, по сравнению с протекшим ионным зарядом, сдвигает порог открытия канала (до 0.5 В, что соответствует количеству ионов $1.1 \cdot 10^{11} \mathrm{~cm}^{-2}$ ). Данное обстоятельство в свою очередь подтверждает известный факт о высокой степени нейтрализации ионов у границы раздела кремний-окисел [7,10-12]. Эффективная подвижность электронов в инверсионном канале

$$
\mu=\left(1 / C_{i}\right) d \sigma / d V_{g}
$$

где $\sigma=\left(I_{d} L / W V_{d}\right)$ - омическая проводимость канала, $I_{d}$ - ток в цепи исток-сток, $C_{i}$ - емкость подзатворного окисла кремния. Величина $\mu$ определялась на участке, где ток $I_{d}$ практически линейно зависел от полевого напряжения $V_{g}$. Поляризация приводит к повышению эффективной подвижности примерно в 2 раза. $^{2}$ Температурные зависимости $\mu(T)$ для поляризованного и деполяризованного состояний показаны на рис. 2. Понижение температуры сопровождается увеличением эффективной подвижности, причем в интервале $100-200 \mathrm{~K} \mu \propto T^{-0.7}$. При дальнейшем уменьшении температуры значение $\mu$ проходит через максимум и далее падает резче, чем степенным образом. Такое поведение подвижности не соответствует проводимости свободных электронов в канале инверсии вдоль поверхности кремния [13].

На рис. 3 представлены зависимости эффективной подвижности в канале транзистора от величины магнит-

\footnotetext{
2 У отдельных транзисторов рост величины эффективной подвижности канала после поляризации был заметно больше, вплоть до 10 раз, и величина $\mu$ превышала значение подвижности электронов в объеме кремния.
}

ного поля в диапазоне температур $100-200 \mathrm{~K}$ в состояниях после поляризации и деполяризации. Наблюдается отрицательная магнетопроводимость: величина $\mu$ уменьшается с ростом магнитной индукции от 1.07 до 4.28 Тл как после поляризации, так и после деполяризации в среднем в 1.3 раза. Данный факт свидетельствует о прыжковом характере проводимости как в поляризованном, так и в деполяризованном состояниях [14]. При этом магнитное поле практически не изменяет порог открытия канала инверсии.

Изменения электропроводности каналов вдоль ГР $\mathrm{Si}-\mathrm{SiO}_{2}$ после поляризации окисла, насыщенного ионами натрия, изучались группой Пеппера [15-18]. Обнаружено, что сосредоточение у ГР $\mathrm{Si}-\mathrm{SiO}_{2}$ относительно небольших концентраций ионов натрия, порядка $3.7 \cdot 10^{11} \mathrm{~cm}^{-2}$, приводит к образованию верхней и ниж-

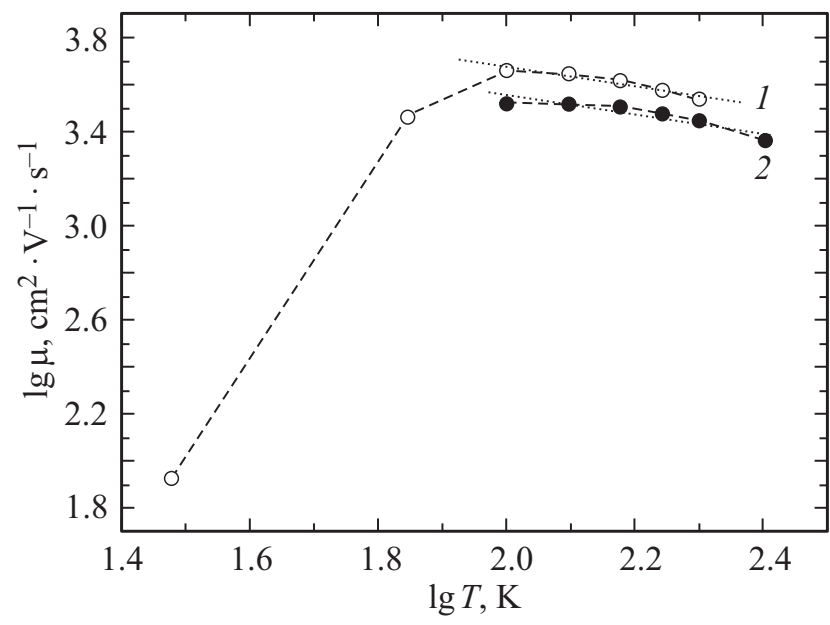

Рис. 2. Температурные зависимости эффективной подвижности электронов в канале инверсии МОП-транзистора: 1 после поляризации, 2 - после деполяризации.

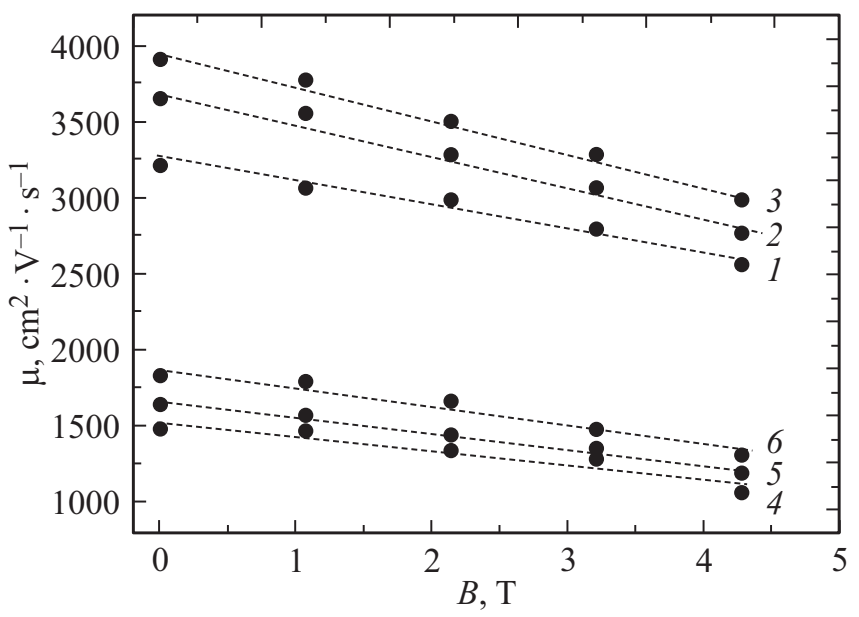

Рис. 3. Зависимости эффективной подвижности электронов в канале инверсии от магнитного поля после поляризации (кривые 1-3) и деполяризации (кривые 4-6); номера кривых: $1,4-200 \mathrm{~K} ; 2,5-150 \mathrm{~K} ; 3,6-100 \mathrm{~K}$. 


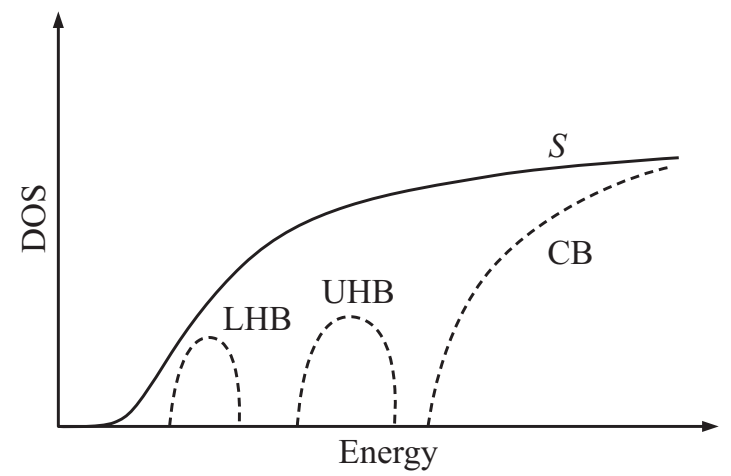

Рис. 4. Вид плотности состояний в канале инверсии транзистора после поляризации. Пунктиром проведены линии, содержащиеся на рис. $1, b$ из работы [16]. LHB - нижняя зона Хаббарда, UHB - верхняя зона Хаббарда, CВ - зона проводимости, $S-$ плотность состояний в канале инверсии после поляризации наших образцов.

ней примесных зон Хаббарда (см. рис. 4). За нижнюю зону ответственны электронные состояния, заполнение которых приводит к нейтрализации ионов натрия. Данная зона расположена на несколько десятков мэВ глубже дна зоны проводимости кремния. Верхняя зона обусловлена запутыванием и делокализацией $\mathrm{D}^{-}$-состояний, ${ }^{3}$ образованных потенциалами нейтральных ионных комплексов, и она отстоит от границы зоны проводимости кремния (без учета размерного квантования электронов в канале инверсии) на 3.9 мэВ. В наших опытах после поляризации транзисторов у ГР $\mathrm{Si}-\mathrm{SiO}_{2}$ оказывается минимум на 2 порядка больше заряженных частиц, чем в образцах, исследованных в [15-18]. Это означает (см. рис. 4), что по сравнению с объектами измерений группы Пеппера в наших образцах связанные с ионами примесные зоны Хаббарда существенно уширены и перекрыты как между собой, так и с зоной проводимости канала инверсии у поверхности кремния. Фактически плотность состояний $S$ описывается одной, монотонно растущей с энергией $E$ кривой, в итоге сливающейся с графиком плотности состояний свободных электронов в зоне проводимости (см. рис. 4). Резко увеличивающиеся в результате поляризации величина $S$ и соответственно проводимость по делокализованным состояниям в итоге и объясняют возрастание эффективной подвижности в канале инверсии транзистора. Относительно слабая и немонотонная зависимость эффективной подвижности от температуры (см. рис. 2) указывает на неактивационный механизм проводимости и тем самым подтверждает отсутствие щелей в спектре плотности состояний. На опыте наблюдается (см. рис. 3) хоть и отрицательная магнетопроводимость, указывающая на прыжковый характер переноса, но со слабой зависимостью от величины магнитной индукции. Дело в том, что после поляризации даже при максимальных значениях исполь-

\footnotetext{
${ }^{3}$ Полная аналогия с $\mathrm{D}^{-}$-центрами, образованными нейтральными донорами в объеме полупроводника [19].
}

зованных нами магнитных полей характерный радиус циклотронной орбиты (магнитная длина) оказывается практически на порядок выше среднего межпримесного расстояния. Поэтому никакого существенного сжатия в магнитном поле волновых функций электронов в зоне состояний, связанных с ионами, не происходит. Соответственно незначительно и влияние магнитной индукции на электроперенос по каналу инверсии транзистора.

\section{4. Заключение}

Таким образом, ионная поляризация окисла позволяет кардинально изменять электронные свойства ГР $\mathrm{Si}-\mathrm{SiO}_{2}$. Резкое повышение концентрации ионов у контакта кремния с окислом приводит к образованию широкой (по энергии) зоны делокализованных примесных состояний в канале инверсии. В результате электропереноса по этой зоне существенно возрастают электронная проводимость вдоль $Г \mathrm{P} \mathrm{Si}-\mathrm{SiO}_{2}$ и величина еe характеристики - эффективной подвижности электронов. Поляризованное состояние окисла достаточно устойчиво и длительно (более месяца) сохраняется при температурах ниже $250 \mathrm{~K}$ даже после подачи на полевой электрод деполяризующих напряжений. Такое свойство изолирующих слоев в кремниевых транзисторах позволяет надеяться на предложенное в $[7,20]$ использование явлений поляризации и деполяризации $\mathrm{SiO}_{2}$ в качестве записывающих и стирающих процессов в устройствах обработки информации.

Работа выполнена при частичной финансовой поддержке гранта РФФИ № 16-07-00666 и Программы фундаментальных исследований президиума РАН № 32 „Наноструктуры: физика, химия, биология, основы технологий“.

\section{Список литературы}

[1] E.H. Nicollian, I.R. Brews. MOS (Metal Oxide Semiconductor) Physics and Technology (N.Y., John Willey @ Sons, 1982).

[2] A. Hartstein, A.B. Fowler. Phys. Rev. Lett., 34, 1435 (1975).

[3] Т. Андо, А. Фаулер, Ф. Стерн. Электронные свойства двумерных систем (М., Мир, 1985).

[4] Е.И. Гольдман, А.Г. Ждан. Письма ЖТФ, 29 (1), 38 (2000).

[5] Е.И. Гольдман, Ю.В. Гуляев, А.Г. Ждан, Г.В. Чучева. Микроэлектроника, 30 (5), 364 (2001).

[6] Ю.В. Гуляев, А.Г. Ждан, Г.В. Чучева. ФТП, 41 (3), 368 (2007).

[7] А.Г. Ждан, В.Г. Нарышкина, Г.В. Чучева. ФТП, 43 (5), 705 (2009).

[8] Е.И. Гольдман, А.Г. Ждан, Г.В. Чучева. ПТЭ, 6, 110 (1997).

[9] Криомагнитная безжидкостная система с индукиией $8 T л$ (М., ЗАО „РТИ, технологии, приборы, материаль“, 2012).

[10] T. Hino, K. Yamashita. J. Appl. Phys., 50 (7), 4879 (1979).

[11] D.J. DiMaria. J. Appl. Phys., 52 (12), 7251 (1981). 
[12] E.I. Goldman, A.G. Zhdan, G.V. Chucheva. J. Appl. Phys., 89 (1), 130 (2001).

[13] В.Н. Добровольский, В.Г. Литовченко. Перенос электронов и дырок у поверхности полупроводников (Киев, Наук. думка, 1985).

[14] Б.И. Шкловский, А.Л. Эфрос. Электронные свойства легированных полупроводников (М., Наука ФМ, 1979).

[15] T. Ferrus, R. George, C.H.W. Barnes, N. Lumpkin, D.J. Paul, M. Pepper. Phys. Rev. B, 73(4), Rapid Communication 041304 (2006).

[16] T. Ferrus, R. George, C.H.W. Barnes, N. Lumpkin, D.J. Paul, M. Pepper. Physica B, 400 (1-2), 218 (2007).

[17] T. Ferrus, R. George, C.H.W. Barnes, N. Lumpkin, D.J. Paul, M. Pepper. J. Phys.: Condens. Matter, 19 (22), 226216 (2007).

[18] T. Ferrus, R. George, C.H.W. Barnes, M. Pepper. Appl. Phys. Lett., 97 (14), 142108 (2010).

[19] Е.М. Гершензон, А.П. Мельников, Р.И. Рабинович, Н.А. Серебрякова. УФН, 132 (2), 353 (1980).

[20] Ю.В. Гуляев, А.Г. Ждан, В.Г. Приходько. Препринт ИРЭ PAH № 46 (М., 1990).

Редактор Г.А. Оганесян

\section{On the nature of an increase of the electron mobility in the inversion channel at the silicon-oxide interface after a field influence}

\section{E.I. Goldman ${ }^{\mathbf{1}}$, A. Nabiev ${ }^{\mathbf{2}}$, V.G. Naryshkina ${ }^{\mathbf{1}}$,} G.V. Chucheva ${ }^{1}$

${ }^{1}$ Fryazino branch of the Kotel'nikov Institute of Radioengineering and Electronics of Russian Academy of Sciences, 141190 Fryazino, Moscow region, Russia

${ }^{2}$ Azerbaijan State Pedagogical University, Az-1000 Baku, Azerbaijan

Abstract Conductivity measurements of the inversion channel of Si-transistor structures after the ion polarization and depolarization of samples in the range of induction values of the transverse magnetic field of the $0-5 \mathrm{~T}$ at temperatures from the $100 \mathrm{~K}$ to the $200 \mathrm{~K}$ were carried out. At a temperature of $420 \mathrm{~K}$ in after the ion polarization under the action of a strong electric field, no less than $6 \cdot 10^{13} \mathrm{~cm}^{-2}$ ions flowed in the oxide. The previously detected increase of the conductivity in the source-drain circuit after the ion polarization of insulating layers up to 10 times is explained by the new path formation of the electron transport along the surface impurity band, associated with delocalized $\mathrm{D}^{-}$states, that are generated by neutralized ions, located in an insulating layer at the interface with a semiconductor. 